\title{
The Warwick Agreement on femoroacetabular impingement syndrome (FAl syndrome): an international consensus statement
}

\author{
D R Griffin, ${ }^{1,2}$ E J Dickenson, ${ }^{1,2}$ J O'Donnell, ${ }_{1}^{3,4}$ R Agricola, ${ }_{1}^{5}$ T Awan, $_{1}^{6}$ M Beck, ${ }^{7}$ \\ J C Clohisy, ${ }^{8}$ H P Dijkstra, ${ }^{9}$ E Falvey, ${ }^{10,11}$ M Gimpel, ${ }^{12}$ R S Hinman, ${ }^{13}$ P Hölmich, ${ }^{9,}{ }^{14}$ \\ A Kassarjian, ${ }^{15,16}$ H D Martin, ${ }^{17}$ R Martin, ${ }^{18,19}$ R C Mather, ${ }^{20}$ M J Philippon, ${ }_{1}{ }^{21}$ \\ M P Reiman, ${ }^{20} \mathrm{~A} \mathrm{Takla}^{3,22,23,24} \mathrm{~K}^{3}$ Thorborg, ${ }^{14} \mathrm{~S}$ Walker, ${ }^{25} \mathrm{~A}$ Weir, ${ }^{9,26} \mathrm{~K} \mathrm{~L}$ Bennell ${ }^{23}$
}

- Additional material is published online only. To view please visit the journal online (http://dx.doi.org/10.1136/ bjsports-2016-096743).

For numbered affiliations see end of article.

\section{Correspondence to} Professor DR Griffin, Clinical Sciences Research Institute, University Hospitals Coventry and Warwickshire, Coventry, CV2 2DX, UK:

damian.griffin@warwick.ac.uk

Accepted 31 July 2016

\section{SLinked}

- http://dx.doi.org/10.1136/ bjsports-2016-096868

CrossMark

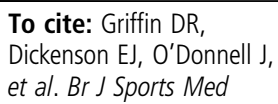

The Warwick Agreement on femoroacetabular impingement syndrome has been endorsed by the following 25 clinical societies: American Medical Society for Sports Medicine (AMSSM), Association of Chartered Physiotherapists in Sports and Exercise Medicine (ACPSEM), Australasian College of Sports and Exercise Physicians (ACSEP), Austian Sports Physiotherapists, British Association of Sports and Exercise Medicine (BASEM), British Association of Sport Rehabilitators and Trainers (BASRaT), Canadian Academy of Sport and Exercise Medicine (CASEM), Danish Society of Sports Physical Therapy (DSSF), European College of Sports and Exercise Physicians (ECOSEP), European Society of Sports Traumatology, Knee Surgery and Arthroscopy (ESSKA), Finnish Sports Physiotherapist Association (SUFT), German-Austrian-Swiss Society for Orthopaedic Traumatologic Sports Medicine (GOTS), International Federation of Sports Physical Therapy (IFSPT), International Society for Hip Arthroscopy (ISHA), Groupo di Interesse Specialistico dell'A.I.F.I., Norwegian Association of Sports Medicine and Physical Activity (NIMF), Norwegian Sports Physiotherapy Association (FFI), Society of Sports Therapists (SST), South African Sports Medicine Association (SASMA), Sports Medicine Australia (SMA), Sports Doctors Australia (SDrA), Sports Physiotherapy New Zealand (SPNZ), Swedish Society of Exercise and Sports Medicine (SFAIM), Swiss Society of Sports Medicine (SGMS/SGSM), Swiss Sports Physiotherapy Association (SSPA).

\section{ABSTRACT}

The 2016 Warwick Agreement on femoroacetabular impingement (FAl) syndrome was convened to build an international, multidisciplinary consensus on the diagnosis and management of patients with FAI syndrome. 22 panel members and 1 patient from 9 countries and 5 different specialties participated in a 1-day consensus meeting on 29 June 2016. Prior to the meeting, 6 questions were agreed on, and recent relevant systematic reviews and seminal literature were circulated. Panel members gave presentations on the topics of the agreed questions at Sports Hip 2016, an open meeting held in the UK on 27-29 June.

Presentations were followed by open discussion. At the 1-day consensus meeting, panel members developed statements in response to each question through open discussion; members then scored their level of agreement with each response on a scale of $0-10$. Substantial agreement (range 9.5-10) was reached for each of the 6 consensus questions, and the associated terminology was agreed on. The term 'femoroacetabular impingement syndrome' was introduced to reflect the central role of patients' symptoms in the disorder. To reach a diagnosis, patients should have appropriate symptoms, positive clinical signs and imaging findings. Suitable treatments are conservative care, rehabilitation, and arthroscopic or open surgery. Current understanding of prognosis and topics for future research were discussed. The 2016 Warwick Agreement on FAI syndrome is an international multidisciplinary agreement on the diagnosis, treatment principles and key terminology relating to FAl syndrome.

\section{INTRODUCTION}

The concept of hip impingement has been appreciated since at least $1936 .{ }^{1}$ Ganz et al discussed femoroacetabular impingement (FAI) in more detail in 2001, reporting a new surgical approach, and then presenting a hypothesis linking FAI with osteoarthritis in $2003 .^{3}$ This, and the introduction of an arthroscopic approach to surgery in the early 2000s, led to increasing interest in this condition; the number of patients identified with FAI has risen rapidly over the past 10 years. ${ }^{4-6}$ In parallel, there has been a rapid increase in the number of publications. In 2012, Clohisy and $\mathrm{Kim}^{7}$ organised a meeting of predominantly orthopaedic surgeons to summarise the literature on FAI, develop consensus and consider how best to design future research. ${ }^{8-13}$

In recent years, the number of patients being treated for FAI has risen sharply in many countries. $^{5} 6{ }^{14}$ Clinicians, funders and health systems are concerned about this rise in a previously unrecognised condition, the costs and uncertainties of treatment, the lack of clarity of the epidemiology and the ambiguity of the diagnostic criteria.

To guide patients, clinicians and funders, we convened a consensus meeting. Our aim was to reach an international multidisciplinary agreement on the diagnosis and management of FAI syndrome.

\section{METHODS}

\section{Panel selection}

We invited representatives from a range of professions and specialties to join a consensus panel. We 
included sport and exercise medicine physicians, physiotherapists, orthopaedic surgeons and radiologists, who are most closely involved in managing these patients. We invited people who were known to have a research interest and clinical practice in FAI syndrome, and asked professional organisations with a known interest to nominate suitable people (International Society for Hip Arthroscopy, International Federation of Sports Physical Therapy and American Medical Society for Sports Medicine). We aimed to have representation from around the world, and deliberately chose people who we knew to hold disparate views, representing as wide a spectrum of opinion as possible. In total, 22 expert clinicians and academics, and 1 patient, from 9 countries and 5 specialties, participated in the process and are the authors of this article.

\section{Preliminary work}

We developed a list of topics and questions that we hoped to answer, circulating ideas around the panel until there was agreement. We searched relevant databases (PubMed and Cochrane Library), with review filter (PubMed), using the search term 'femoroacetabular impingement' from inception to 18 March 2016 for published articles relevant to these topics. A list of articles consisting of recent systematic reviews and original seminal research relevant to these topics was prepared; panel members suggested additional articles where important research had been omitted. The revised selection of publications was provided to all panel members along with the following final questions:

- What is FAI syndrome? ? $^{35-17}$

- How should FAI syndrome be diagnosed? ? $^{11} 18-21$

- What is the appropriate treatment of FAI syndrome? ${ }^{92-28}$

- What is the prognosis of FAI syndrome? ${ }^{13} 29$

- How should someone with an asymptomatic hip with cam or pincer morphology be managed? 31

- Which outcome measures should be used to assess treatment for FAI syndrome? $?^{32-34}$

-What future research needs to be conducted?

\section{Open meeting}

Panel members gave presentations at Sports Hip 2016 (http:// www.sportshipsurgery.org), an open meeting held in the UK on 27-28 June 2016. One hundred and fifty international delegates from a range of clinical backgrounds (surgeons, radiologists, physiotherapists and sport and exercise medicine doctors) familiar with managing young adult hip pathology attended the conference. Panel members' presentations explored each topic with an emphasis on the highest levels of evidence, from systematic reviews and randomised controlled trials where available. After each presentation, DRG chaired an open discussion where all delegates and the panel members discussed each topic.

\section{Agreement meeting}

On 29 June 2016, the panel met at the University of Warwick to formulate the agreement statement. The meeting was chaired by EJD who did not express opinions during the discussion.

For each topic, the chairman facilitated a structured discussion leading to a proposed wording for consideration. Panel members then voted on each proposal on a Likert scale of $0-10$, where 0 reflected complete disagreement, 5 neither agreement nor disagreement and 10 complete agreement. Levels of agreement were summarised with mean scores and 95\% CIs. Discussions continued until a mean score of $>7.5$ was reached, or until the chairman deemed that no further compromise could be found.

A different approach was taken when discussing what future research is needed. Delegates at Sports Hip 2016, including panel members, were invited to suggest their opinions as to the most important research questions that need to be answered in order to improve the management of FAI syndrome. EJD and KB collated responses. We used a web-based prioritisation programme (http://www.1000minds.com) to order these research questions. This software presented panel members with pairs of research questions and asked them to choose the more important of the two. Repeated pairwise comparisons, across all panel members, led to an ordered list of research questions. During the agreement meeting, the panel used this ordered list of research questions as a basis for open discussion and development of research themes.

\section{RESULTS}

The results of the consensus process (the Warwick International Agreement) are summarised in online supplementary file A. In the following paragraphs, we present the agreed statements for each topic or question (in shading), followed by a summary of the panel's consensus discussions.

\section{What is FAl syndrome?}

FAl syndrome is a motion-related clinical disorder of the hip with a triad of symptoms, clinical signs and imaging findings. It represents symptomatic premature contact between the proximal femur and the acetabulum.

Level of agreement: mean score 9.8 (95\% Cl 9.6 to 10).

\section{DISCUSSION}

FAI was described by Ganz et $a l^{3}$ as a condition of "abnormal contact that may arise as a result of either abnormal morphological features...or as a result of subjecting the hip to excessive and supraphysiological range of motion". Sankar $e t a l^{13}$ further developed this definition, describing 'five essential elements':

- Abnormal morphology of the femur and/or acetabulum;

- Abnormal contact between these two structures;

- Especially vigorous supraphysiological motion that results in such abnormal contact and collision;

- Repetitive motion resulting in the continuous insult;

- The presence of soft-tissue damage.

We felt that these definitions do not sufficiently emphasise patients' symptoms. Ambiguity as to the role of symptoms in making a diagnosis of FAI has led to the introduction of new terms such as 'asymptomatic FAI' or 'radiological FAI', ${ }^{35-37}$ apparently to describe hip morphologies rather than a clinical disorder. ${ }^{19}$ We agreed that this creates confusion when trying to define the clinical disorder.

To make clear the need for symptoms to be present, the panel proposed the new term 'femoroacetabular impingement syndrome', or 'FAI syndrome'. ${ }^{38}$ We considered other terms, for example, hip impingement syndrome, but preferred FAI syndrome as this did not include extra-articular hip impingement such as ischiofemoral or greater trochanteric impingement. We considered whether 'syndrome' might apply a negative label to patients, but the expert patient member of the panel did not feel this would be the case.

We defined FAI syndrome as a triad of symptoms, clinical signs and imaging findings. ${ }^{3}{ }^{13}$ This term and its definition build on the definitions of FAI from Ganz et al and Sankar et al, but emphasise that symptoms, clinical signs and relevant imaging findings must all be present for diagnosis

To ensure that there is a distinction between patients with FAI syndrome and those with cam or pincer morphology but no 
Table 1 Agreement on terminology relating to femoroacetabular impingement (FAI)

\begin{tabular}{|c|c|}
\hline $\begin{array}{l}\text { Recommended } \\
\text { terminology }\end{array}$ & Terminology to be avoided \\
\hline FAl syndrome & Asymptomatic FAl \\
\hline Cam morphology & Symptomatic FAI \\
\hline \multirow[t]{2}{*}{ Pincer morphology } & FAI morphology \\
\hline & $\begin{array}{l}\text { Deformity, abnormality or lesion when referring to } \\
\text { cam or pincer morphology }\end{array}$ \\
\hline \multicolumn{2}{|c|}{ Level of agreement: mean score 10 (95\% Cl 9.8 to 10$)$} \\
\hline
\end{tabular}

clinical disorder, the panel recommends that certain terminology be used while we cease to use other terms that were considered confusing (see table 1).

\section{How should FAl syndrome be diagnosed?}

Symptoms, clinical signs and imaging findings must be present to diagnose FAI syndrome.

Level of agreement: mean score 9.8 (95\% Cl 9.6 to 10).

\section{Symptoms}

The primary symptom of FAl syndrome is motion-related or position-related pain in the hip or groin. Pain may also be felt in the back, buttock or thigh. In addition to pain, patients may also describe clicking, catching, locking, stiffness, restricted range of motion or giving way.

Level of agreement: mean score 9.8 (95\% Cl 9.6 to 10).

\section{DISCUSSION}

The primary symptom of FAI syndrome is pain. ${ }^{3}$ However, there is wide variation in the location, nature, radiation, severity and precipitating factors that characterise this pain. Most patients report pain in the groin or hip, but pain is also reported in the lateral hip, anterior thigh, buttock, knee, lower back, lateral and posterior thigh. ${ }^{39}$ Pain in FAI syndrome is typically motion-related or position-related; we recognised that this encompasses a wide range of patients, from those who experience symptoms during or after vigorous activity (eg, football), to those who have pain with a supraphysiological range of motion (eg, dance, gymnastics), to those who get symptoms despite leading a sedentary lifestyle (seated for long periods). ${ }^{3} 3940$ We agreed that mechanical symptoms, such as clicking, catching, locking, giving way or stiffness are also reported by many patients with FAI syndrome. ${ }^{39}$

We discussed the common problem of determining whether pain is really arising from the hip joint or from other structures in the groin and hip region. We agreed that image-guided (X-ray or ultrasound) local anaesthetic injections are useful in helping to resolve this situation. ${ }^{41} 42$ Pain relief following a local anaesthetic injection would support a diagnosis of FAI syndrome, when the other diagnostic criteria are met. ${ }^{43}$

In most patients who seek treatment for FAI syndrome, symptoms are not mild or subtle. They are often severe and limiting in everyday life. The panel felt that this is especially important because patients are usually young, economically active adults. Symptoms of
FAI syndrome therefore lead to a significant and lasting cost burden for society as well as being individually debilitating. ${ }^{44}$

\section{Clinical signs}

Diagnosis of FAl syndrome does not depend on a single clinical sign; many have been described and are used in clinical practice. Hip impingement tests usually reproduce the patient's typical pain; the most commonly used test, flexion adduction internal rotation (FADIR), is sensitive but not specific. There is often a limited range of hip motion, typically restricted internal rotation in flexion.

Level of agreement: mean score 9.9 (95\% Cl 9.7 to 10).

\section{DISCUSSION}

We discussed the need for a comprehensive hip and groin examination, as part of the determination of a diagnosis of FAI syndrome. ${ }^{45}$

Many examination techniques and clinical signs for FAI syndrome have been described, but we agreed that there are several problems. Different clinicians apply and interpret clinical tests differently, with little consistency between professional groups or among peers. ${ }^{45} 46$ Even when tests are well defined, they have often been evaluated in populations with a high likelihood of a positive test, ${ }^{18}$ so their performance in a different environment (such as primary care) is not known. The most wellknown test, the FADIR impingement test, is sensitive (usually positive when FAI syndrome is present), but not specific (often positive when FAI syndrome is not the correct diagnosis). ${ }^{18}$ The evidence on hip range of motion (ROM) in FAI syndrome is surprisingly contradictory, ${ }^{16}{ }^{47}$ but the panel felt that on balance FAI syndrome is associated with a restricted hip ROM.

We also recognised that abnormal movement patterns around the hip and pelvis are present in patients with FAI syndrome. $^{47} 48$ These movement patterns, associated with FAI syndrome, may lead to pain or dysfunction in other regions, such as the spine, pelvis, posterior hip or abdominal wall. ${ }^{47}$ Furthermore, muscles around the hip are frequently weak in patients with FAI syndrome. ${ }^{16}$

The panel concluded that when FAI syndrome is suspected, it is important to examine gait, single leg control, muscle tenderness around the hip and hip ROM including internal rotation in flexion and the FABER distance (flexion abduction external rotation). Impingement testing should be performed, and to be positive it must reproduce the patient's familiar pain. It is essential to examine the groin for other structures that can produce similar pain.

\section{Diagnostic imaging}

An anteroposterior radiograph of the pelvis and a lateral femoral neck view of the symptomatic hip should initially be performed to obtain an overview of the hips, identify cam or pincer morphologies, and identify other causes of hip pain. Where further assessment of hip morphology and associated cartilage and labral lesions is desired, cross-sectional imaging is appropriate.

Level of agreement: mean score 9.5 (95\% Cl 9.1 to 9.8). 


\section{DISCUSSION}

Morphological assessment of the hip is required in order to diagnose FAI syndrome, identifying cam or pincer morphology. Cam morphology refers to a flattening or convexity at the femoral head neck junction. ${ }^{3}$ Pincer morphology refers to either global or focal overcoverage of the femoral head by the acetabulum. ${ }^{3}$ The panel emphasised that their presence, in the absence of appropriate symptoms and clinical signs, does not constitute a diagnosis of FAI syndrome. A substantial proportion of people in the general population are thought to have cam or pincer morphology. 1949

We agreed that radiological assessment is best achieved initially with plain radiographs. A pelvic radiograph allows an overall assessment of the pelvis and hips, and exclusion of other painful conditions such as fracture, acetabular dysplasia and osteoarthritis. Ideally, this radiograph should be centred on the pubic symphysis, without rotation, and with neutral pelvic tilt. $^{3} 50$ The shape of the acetabulum can be interpreted from this radiograph, ${ }^{51}$ but visualising the shape of the proximal femur requires an orthogonal view of the femoral neck. A number of such views have been described such as the crosstable lateral, Dunn and frog laterals. ${ }^{52}$

There are some difficulties in interpreting three-dimensional (3D) shapes from plain radiographs. For example, the spatial orientation of the acetabulum may be affected by the position of the pelvis. Posterior tilt increases in standing position and the parameters that describe anterior and posterior acetabular coverage, which are important in describing pincer morphology, may change. $^{50} 53$ Also, two orthogonal views of the femoral neck may not be sufficient to identify all instances of cam morphology. ${ }^{21}$ In combination, these radiographs are only moderately sensitive for identifying the typical morphology of FAI syndrome, but are specific. ${ }^{21}$

We agreed that morphology can be better characterised through cross-sectional imaging, either CT or MRI. ${ }^{21}{ }^{54}$ This is particularly important if surgery is being considered. MR arthrography is usually more accurate than plain MRI to assess the labrum and articular cartilage. ${ }^{55} 56$ MRI may also identify other soft tissue lesions that may result in hip or groin pain. When performing cross-sectional imaging of the hip in FAI syndrome, limited images of the distal femoral condyles allow assessment of femoral torsion, while 3D reformatting of CT or radial MRI allows assessment of focal morphological abnormalities, particularly of the proximal femur. ${ }^{57}$

Many radiographic measures of cam and pincer morphology have been described including the $\alpha$ angle (cam), cross-over sign and centre-edge angle (pincer). ${ }^{58-60}$ Some clinical trials (e.g. UK FASHIoN) of treatments for FAI syndrome have included patients with an $\alpha$ angle $>55^{\circ}$ at any position on the head neck junction for cam morphology and a positive cross-over sign or a centre edge angle $>39^{\circ}$ for pincer morphology. ${ }^{14}$ However $\alpha$ angles cannot accurately discriminate between patients with cam type FAI syndrome and asymptomatic volunteers, despite changes to the threshold value. ${ }^{20}$

The panel was unable to recommend precise diagnostic values for any of the common measures to define cam or pincer morphology in routine clinical practice. This is because we recognised that impingement is the result of a complex interaction, during motion, between the acetabulum and femoral neck. We agreed that the depth, orientation and rim of the acetabulum, and the head-neck profile, neck angle and torsion of the proximal femur all vary in the general population. It is when a particularly unfavourable combination of these characteristics occur together, along with provocative movement or position, that a patient may present with FAI syndrome. It has not been possible to capture all of this in a single measurement or even a simple set of shape criteria.

\section{What is the appropriate treatment of FAl syndrome?}

FAl syndrome can be treated by conservative care, rehabilitation or surgery. Conservative care may involve education, watchful waiting, lifestyle and activity modification. Physiotherapy-led rehabilitation aims to improve hip stability, neuromuscular control, strength, range of motion and movement patterns. Surgery, either open or arthroscopic, aims to improve the hip morphology and repair damaged tissue. The good management of the variety of patients with FAI syndrome requires the availability of all of these approaches.

Level of agreement: mean score 9.5 (95\% Cl 9.0 to 10).

\section{DISCUSSION}

Treatment strategies for FAI syndrome have included conservative care, rehabilitation and surgery. The panel agreed that each of these may have a role in different patients, but that there is little evidence to compare their effectiveness. Figure 1 is a suggested pathway for the management of FAI syndrome.

There is currently no high-level evidence to support the choice of a definitive treatment for FAI syndrome. ${ }^{22}{ }^{23}$ For any one patient, the panel agreed that it is appropriate to consider the different treatment options. This is best done in a shared decision-making process, supporting the individual patient to make an informed preference decision on the best treatment option for them. ${ }^{61}{ }^{62}$ We agreed that those treating FAI syndrome, particularly in secondary and tertiary care, should be part of a multidisciplinary group with knowledge of, and access to, all the treatment options.

Conservative care of patients with FAI syndrome is poorly described but could include patient education, activity and lifestyle modification, oral analgesia including non-steroidal anti-inflammatory drugs, intra-articular steroid injection and watchful waiting. ${ }^{23}$ There are no reports of what effect such an approach, in isolation, has on the symptoms of FAI syndrome. Similar conservative strategies are recommended in other musculoskeletal disorders such as hip osteoarthritis. ${ }^{63} 64$

Physiotherapist-led rehabilitation aims to reduce patients' symptoms by improving hip stability, neuromuscular control and movement patterns. $^{23}$ The treatment targets for rehabilitation are wide-ranging and include improving sagittal and frontal plane hip range of motion, hip muscle strengthening and lumbopelvic dissociation. ${ }^{14474865}$ However, details of what should be incorporated in such a programme has not been well tested and it would appear that different physiotherapists are delivering different treatments. ${ }^{23}$

Surgery aims to correct hip morphology to achieve impingementfree motion. Cam morphology can be reshaped and femoral torsion or neck angle adjusted; the acetabulum can be reorientated or its rim trimmed. Where there is damage to the labrum or articular cartilage, this can be resected, repaired or reconstructed. Often, these procedures can be done by either arthroscopic or open surgery. ${ }^{2} 4$ An arthroscopic approach may be preferable in many patients to allow rapid recovery, but some of these procedures will require an open approach. Postoperative physiotherapy protocols have been described but their value is uncertain. ${ }^{66-68}$ 
Figure 1 Pathway for the management of femoroacetabular impingement (FAI) syndrome.

\section{What is the prognosis of FAI syndrome?}

In patients who are treated for FAl syndrome, symptoms frequently improve, and they return to full activity, including sports. Without treatment, symptoms of FAI syndrome will probably worsen over time. The long-term outlook for patients with FAI syndrome is unknown. However, it is likely that cam morphology is associated with hip osteoarthritis. It is currently unknown whether treatment for FAI syndrome prevents hip osteoarthritis.

Level of agreement: mean score 9.6 (95\% Cl 9.3 to 9.8).

\section{DISCUSSION}

The panel agreed that patients with FAI syndrome who are not treated probably experience a gradual deterioration of symptoms. ${ }^{69}$ We do not know of any reports of the outcomes of conservative care. Physiotherapy-led rehabilitation seems to be associated with an improvement in symptoms for at least 2 years. $^{23}{ }^{70}$ However, the studies supporting this are only a few observational studies with small sample sizes and important methodological weaknesses. ${ }^{23}$ Reports of the results of surgery are more numerous and describe significant improvement in symptoms up to 5 years, ${ }^{71}$ but they suffer similar issues of poor design and therefore high risk of bias. ${ }^{22}$ Longer term results have been reported for open surgery, including improved symptoms persisting in most patients for at least 10 years. ${ }^{72}$
Clinical signs consistent with

FAl syndrome (e.g restricted ROM or positive impingement test

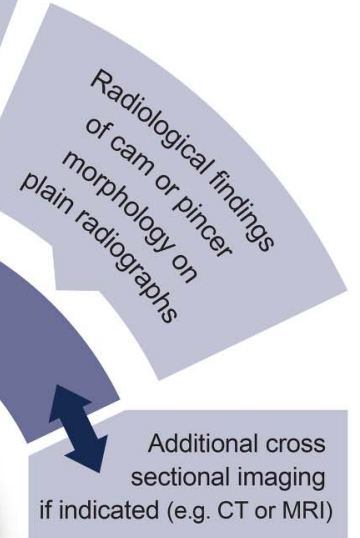

DIAGNOSIS Femoroacetabular indicated (e.g. CT or MRI)

Impingement

Syndrome

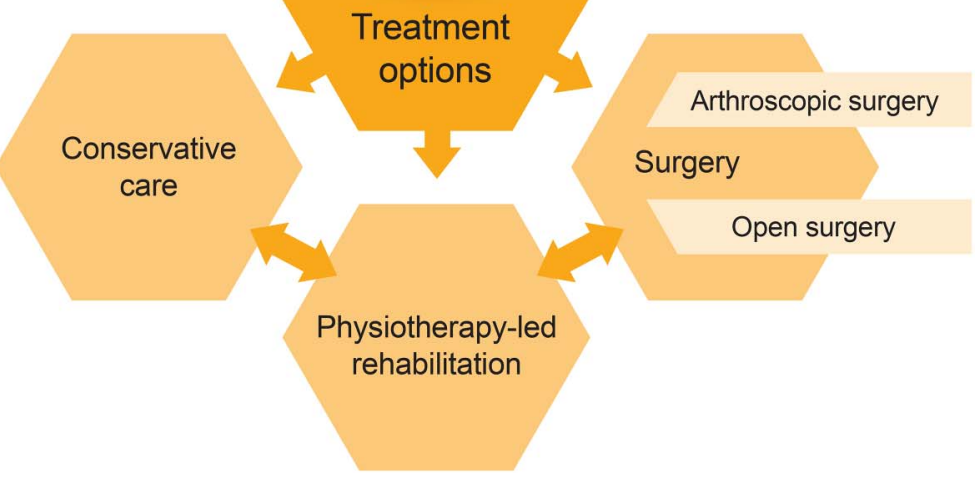

All prospective cohort studies available demonstrate an association between cam morphology and osteoarthritis of the hip. ${ }^{73-76}$ These studies have not found a similar association between pincer morphology and osteoarthritis. We are unable to say whether FAI syndrome is associated with a higher risk of osteoarthritis than isolated cam morphology, but the panel thought it was likely. There is no evidence that treatment for FAI syndrome alters the risk of subsequent osteoarthritis.

\section{How should someone with an asymptomatic hip with cam or pincer morphology be managed?}

It is not known which individuals with cam or pincer morphologies will develop symptoms and, therefore, FAl syndrome. Preventive measures may have a role in higher risk populations, but it is rarely indicated to offer surgery to these individuals.

Level of agreement: mean score 9.6 (95\% Cl 9.4 to 9.8).

\section{DISCUSSION}

There is no evidence that treating people who do not have pain, but who do have cam or pincer morphology, will alter the risk of them developing FAI syndrome or osteoarthritis, and so it is rarely indicated to offer surgery to these people. Preventative physiotherapy-led rehabilitation and conditioning strategies may be appropriate in professional athletes where the prevalence of cam morphology is high, such as 
Table 2 Randomised clinical trials comparing arthroscopic surgery with non-operative care or sham surgery for femoroacetabular impingement syndrome

\begin{tabular}{lllll}
\hline Trial & Trial ID & Country & Sample Size & Interventions \\
\hline UK FASHIoN & ISRCTN64081839 & UK & 344 & Arthroscopic surgery vs physiotherapy \\
Aus FASHIoN & ACTRN12615001177549 & Australia & 120 & Arthroscopic surgery vs physiotherapy \\
FAIT & NCT01893034 & UK & 120 & Arthroscopic surgery vs physiotherapy \\
FIRST & NCT01623843 & Canada and Finland & 220 & Arthroscopic surgery vs arthroscopic washout \\
HIPARTI & NCT02692807 & Norway and Australia & 140 & Arthroscopic surgery vs diagnostic arthroscopy \\
US MHS & NCT01993615 & USA & 60 & Arthroscopic surgery vs physiotherapy \\
\hline
\end{tabular}

US MHS, United States Military Health System FAI Trial.

professional football teams. ${ }^{77}$ In exceptional circumstances, and in a shared decision-making process with a patient, surgery may occasionally be appropriate for high-risk patients. An example of such a patient could be an active young adult who has had surgery for FAI syndrome in one hip and in whom chondrolabral injury is seen to be developing in the other (painless) hip. ${ }^{78}$ In such cases, careful consideration must be given to the risks of surgery and its unknown longterm outcome as well as to the uncertain risks of worsening degeneration and the onset of symptoms.

\section{Which outcome measures should be used to assess}

treatment for FAl syndrome?

Specifically designed and well-validated patient-reported outcome measures should be used to assess treatment for FAI syndrome. The international Hip Outcome Tool (iHOT), Hip and Groin Outcome Score (HAGOS) and Hip Outcome Score (HOS) are recommended.

Level of agreement: mean score 9.7 (95\% Cl 9.4 to 9.9).

\section{DISCUSSION}

The iHOT-12 and iHOT-33, HAGOS, and HOS are valid measures to assess young adults with hip joint pain. We recommend these instruments for use in clinical practice and research. $^{33} 347980$ For FAI syndrome in particular, iHOT and HAGOS were patient-derived in populations of patients including those treated for FAI syndrome, and so can be expected to perform well in this group. Both have sound psychometric properties including test-retest reliability, responsiveness, content validity, and construct validity.

In addition to the hip-specific outcome measures, general quality of life instruments such as the EQ-5D, SF12/36 or PROMIS are recommended. ${ }^{81-83}$ These instruments may not be necessary for routine clinical decision-making and assessment of FAI syndrome, but they have a role in facilitating economic analyses and relative comparisons to other conditions and treatments as part of clinical research and health policy development.

\section{What future research needs to be conducted?}

\section{DISCUSSION}

The delegates at Sports Hip 2016 proposed 118 research questions about the diagnosis and management of FAI syndrome. During the consensus exercise, we identified 23 substantially different questions, which were ranked in order of priority by the panel (see online supplementary file B). The panel grouped the questions into four categories: aetiology, diagnosis, prognosis and effect of treatment.

Regarding aetiology, there was considerable interest in how cam and pincer morphologies develop, whether sporting activity in childhood may influence this, and why some patients develop symptoms and others do not.

For diagnosis, we agreed that diagnostic criteria are imprecise and need to be improved, and that the utility of those we have is unclear. We would benefit considerably from better information on the long-term natural history of FAI syndrome, though the panel recognised that significant resources are needed to perform the necessary long-term prospective studies. Finally, there is an urgent need to compare the effectiveness of conservative, rehabilitation and surgical treatment strategies. Fortunately, several such studies are in progress (see table 2), and results will begin to appear in the next few years.

\section{CONCLUSION}

We provide an international, multidisciplinary agreement statement on FAI syndrome. Key messages from this agreement are summarised in a linked infographic. ${ }^{84}$ The term 'FAI syndrome' emphasises the fact that the patients in discussion are symptomatic, suffering from a clinical disorder that is characterised by a triad of symptoms, clinical signs and radiological findings.

\footnotetext{
Author affiliations

${ }^{1}$ Warwick Medical School, University of Warwick, Coventry, UK

${ }^{2}$ University Hospitals of Coventry and Warwickshire NHS Trust, Coventry, UK

${ }^{3}$ Hip Arthroscopy Australia, Melbourne, Victoria, Australia

${ }^{4}$ St Vincents Private Hospital, East Melbourne, Victoria, Australia

${ }^{5}$ Department of Orthopaedics, Erasmus University Medical Centre, Rotterdam, The Netherlands

${ }^{6}$ Medsport, Department of Orthopaedic Surgery, University of Michigan, Ann Arbor, Michigan, USA

${ }^{7}$ Department of Clinic of Orthopaedic and Trauma Surgery, Luzerner Kantonspital, Luzern, Switzerland

${ }^{8}$ Department of Orthopaedic Surgery, Washington University School of Medicine

St. Louis, St. Louis, Missouri, USA

${ }^{9}$ Aspetar, Qatar Orthopaedic and Sports Medicine Hospital, Doha, Qatar

${ }^{10}$ Sports Surgery Clinic, Dublin, Ireland

${ }^{11}$ Department of Medicine, University College Cork, Cork, Ireland

${ }^{12}$ Southampton Football Club, UK

${ }^{13}$ Department of Physiotherapy, The University of Melbourne, Melbourne, Victoria, Australia

${ }^{14}$ Department of Orthopaedic Surgery, Sports Orthopaedic Research Center (SORC-C), Copenhagen University Hospital, Amager-Hvidovre, Denmark

${ }^{15}$ Corades, LLC, Brookline, Massachusetts, USA

${ }^{16}$ Medical Service, Madrid Open Tennis, Madrid, Spain

${ }^{17}$ Hip Preservation Center, Baylor University Medical Center at Dallas, Dallas, Texas, USA

${ }^{18}$ Rangos School of Health Sciences, Physical Therapy, Duquesne University, Pittsburgh, Pennsylvania, USA
} 
${ }^{19}$ UPMC Center for Sports Medicine, Pittsburgh, Pennsylvania, USA

${ }^{20}$ Department of Orthopaedic Surgery, Duke University Medical Center, Durham, North Carolina, USA

${ }^{21}$ Steadman Philippon Research Institute, Vail, Colorado, USA

${ }^{22}$ Australian Sports Physiotherapy

${ }^{23}$ Department of Physiotherapy, The University of Melbourne, Centre for Health, Exercise and Sports Medicine, Melbourne, Victoria, Australia

${ }^{24}$ Bond University

${ }^{25}$ Coventry, UK

${ }^{26}$ Amsterdam Centre for Evidence-based Sports Medicine, Academic Medical Centre, Amsterdam, The Netherlands

Twitter follow Damian Griffin @DamianGriffin \#warwickagreement

Acknowledgements The authors wish to acknowledge Michelle Hall for her help in identifying the relevant systematic reviews for each topic, and Rachel Hobson and James Griffin for their support in running the meeting.

Contributors DRG, JO, KB, RH and EJD had the idea to perform this study and identified potential panel members. DRG, EJD, KB and JO designed the study. EJD collected and distributed the bibliography, coordinated the development of topics and chaired the consensus meeting. All authors contributed to the development of the content of the agreements statement by participating in the meeting or discussions afterwards and voted to indicate their agreement. DRG and EJD wrote the first draft of the paper; all authors helped edit the manuscript and approved the final version.

Funding This project was partially funded by the National Institute for Health Research (NIHR; Health Technology Assessment programme; 13/103/02) and by a research grant from the International Society of Hip Arthroscopy.

Disclaimer The views and opinions expressed therein are those of the authors and do not necessarily reflect those of the Health Technology Assessment Programme, NIHR, National Health Service (NHS) or the Department of Health.

Competing interests See online supplementary file $\mathrm{C}$.

Provenance and peer review Not commissioned; externally peer reviewed.

\section{REFERENCES}

1 Smith-Petersen M. Treatment of malum coxae senilis, old slipped upper femora epiphysis, intrapelvic protrusion of the acetabulum, and coxa plana by means of acetabuloplasty. J Bone Joint Surg Am 1936;18:869-80.

2 Ganz R, Gill T, Gautier E, et al. Surgical dislocation of the adult hip. Bone Joint J 2001;83:1119-24.

3 Ganz R, Parvizi J, Beck M, et al. Femoroacetabular impingement: a cause for osteoarthritis of the hip. Clin Orthop Relat Res 2003;417:112-20.

4 Sampson TG. Arthroscopic treatment of femoroacetabular impingement. Tech Orthop 2005;20:56-62.

5 Colvin AC, Harrast J, Harner C. Trends in hip arthroscopy. J Bone Joint Surg Am 2012;94:e23.

6 Montgomery SR, Ngo SS, Hobson T, et al. Trends and demographics in hip arthroscopy in the United States. Arthroscopy 2013;29:661-5.

7 Clohisy JC, Kim YJ. Femoroacetabular impingement research symposium. J Am Acad Orthop Surg 2013;21(Suppl 1):vi-viii.

8 Nepple JJ, Prather $\mathrm{H}$, Trousdale RT, et al. Diagnostic imaging of femoroacetabular impingement. J Am Acad Orthop Surg 2013;21:S20-6.

9 Nepple JJ, Byrd JT, Siebenrock KA, et al. Overview of treatment options, clinical results, and controversies in the management of femoroacetabular impingement. J Am Acad Orthop Surg 2013;21:553-8.

10 Clohisy JC, Baca G, Beaule PE, et al. Descriptive epidemiology of femoroacetabular impingement: a North American cohort of patients undergoing surgery. Am J Sports Med 2013:41:1348-56.

11 Nepple JJ, Prather H, Trousdale RT, et al. Clinical diagnosis of femoroacetabular impingement. J Am Acad Orthop Surg 2013;21:S16-19.

12 Clohisy JC, Kim Y-J, Lurie J, et al. Clinical trials in orthopaedics and the future direction of clinical investigations for femoroacetabular impingement. I Am Acad Orthop Surg 2013;21:S47-52.

13 Sankar WN, Nevitt M, Parvizi J, et al. Femoroacetabular impingement: defining the condition and its role in the pathophysiology of osteoarthritis. J Am Acad Orthop Surg 2013;21(Suppl 1):S7-S15.

14 Griffin DR, Wall PD, Realpe A, et al. UK FASHIoN: Feasibility study of a randomised controlled trial of arthroscopic surgery for hip impingement compared with best conservative care. Health Technol Assess 2016;20:1-172.

15 Reiman MP, Thorborg K, Hölmich P. Femoroacetabular impingement surgery is on the rise-but what is the next step? J Orthop Sports Phys Ther 2016:46:406-8.

16 Freke MD, Kemp J, Svege I, et al. Physical impairments in symptomatic femoroacetabular impingement: a systematic review of the evidence. $\mathrm{Br} / \mathrm{Sports}$ Med 2016:50:1180
17 Agricola R, Weinans H. What is femoroacetabular impingement? Br I Sports Med 2016:50:196-7

18 Reiman MP, Goode AP, Cook CE, et al. Diagnostic accuracy of clinical tests for the diagnosis of hip femoroacetabular impingement/labral tear: a systematic review with meta-analysis. Br J Sports Med 2015;49:811.

19 Dickenson E, Wall PD, Robinson B, et al. Prevalence of cam hip shape morphology: a systematic review. Osteoarthr Cartil 2016;24:949-61.

20 Sutter R, Dietrich TJ, Zingg PO, et al. How useful is the alpha angle for discriminating between symptomatic patients with cam-type femoroacetabular impingement and asymptomatic volunteers? Radiology 2012;264:514-21.

21 Rakhra KS, Sheikh AM, Allen D, et al. Comparison of MRI alpha angle measurement planes in femoroacetabular impingement. Clin Orthop Relat Res 2009:467:660-5.

22 Wall PD, Brown JS, Parsons N, et al. Surgery for treating hip impingement (femoroacetabular impingement). The Cochrane Library, 2014.

23 Wall PD, Fernandez M, Griffin DR, et al. Nonoperative treatment for femoroacetabular impingement: a systematic review of the literature. $P M R$ 2013:5:418-26

24 Nwachukwu BU, Rebolledo BJ, McCormick F, et al. Arthroscopic versus open treatment of femoroacetabular impingement a systematic review of medium-to long-term outcomes. Am J Sports Med 2016;44:1062-8.

25 Malviya A, Raza A, Jameson S, et al. Complications and survival analyses of hip arthroscopies performed in The National Health Service in England: a review of 6,395 cases. Arthroscopy 2015;31:836-42.

26 Lodhia P, Gui C, Chandrasekaran S, et al. The economic impact of acetabular labral tears a cost-effectiveness analysis comparing hip arthroscopic surgery and structured rehabilitation alone in patients without osteoarthritis. Am I Sports Med 2016:44:1771-80.

27 Alradwan H, Philippon MJ, Farrokhyar F, et al. Return to preinjury activity levels after surgical management of femoroacetabular impingement in athletes. Arthroscopy 2012;28:1567-76

28 Ayeni $\mathrm{O}$, Adamich J, Farrokhyar F, et al. Surgical management of labral tears during femoroacetabular impingement surgery: a systematic review. Knee Surg Sports Traumatol Arthrosc 2014;22:756-62.

29 Kowalczuk M, Yeung M, Simunovic N, et al. Does femoroacetabular impingement contribute to the development of hip osteoarthritis? A systematic review. Sports Med Arthrosc Rev 2015:23:174-9.

30 Collins JA, Ward JP, Youm T. Is prophylactic surgery for femoroacetabular impingement indicated? A systematic review. Am J Sports Med 2014;42: $3009-15$

31 Freeman CR, Azzam MG, Leunig M. Hip preservation surgery: surgical care for femoroacetabular impingement and the possibility of preventing hip osteoarthritis. J Hip Preserv Surg 2014;1:46-55.

32 Harris-Hayes $\mathrm{M}$, McDonough $\mathrm{CM}$, Leunig $\mathrm{M}$, et al. Clinical outcomes assessment in clinical trials to assess treatment of femoroacetabular impingement: use of patient-reported outcome measures. J Am Acad Orthop Surg 2013:21:S39.

33 Thorborg K, Hölmich P, Christensen R, et al. The Copenhagen Hip and Groin Outcome Score (HAGOS): development and validation according to the COSMIN checklist. Br J Sports Med 2011;45:478-91.

34 Mohtadi NG, Griffin DR, Pedersen ME, et al. The development and validation of a self-administered quality-of-life outcome measure for young, active patients with symptomatic hip disease: the International Hip Outcome Tool (iHOT-33). Arthroscopy 2012;28:595-610.

35 Hack K, Di Primio G, Rakhra K, et al. Prevalence of cam-type femoroacetabular impingement morphology in asymptomatic volunteers. J Bone Joint Surg Am 2010;92:2436-44

36 Laborie LB, Lehmann TG, Engesaeter IO, et al. Prevalence of radiographic findings thought to be associated with femoroacetabular impingement in a population-based cohort of 2081 healthy young adults. Radiology 2011;260:494-502.

37 Reichenbach S, Leunig M, Werlen S, et al. Association between cam-type deformities and magnetic resonance imaging-detected structural hip damage: a cross-sectional study in young men. Arthritis Rheum 2011;63:4023-30.

38 Reiman MP, Thorborg K. Femoroacetabular impingement surgery: are we moving too fast and too far beyond the evidence? Br I Sports Med 2015;49: $782-4$

39 Clohisy JC, Knaus ER, Hunt DM, et al. Clinical presentation of patients with symptomatic anterior hip impingement. Clin Orthop Relat Res 2009;467: 638-44.

40 Ayeni OR, Naudie D, Crouch S, et al. Surgical indications for treatment for femoroacetabular impingement with surgical hip dislocation. Knee Surg Sports Traumatol Arthrosc 2013:21:1676-83.

41 Kivlan BR, Martin RL, Sekiya JK. Response to diagnostic injection in patients with femoroacetabular impingement, labral tears, chondral lesions, and extra-articular pathology. Arthroscopy 2011;27:619-27.

42 Bray ED, Sherafati M, Cutts CL, et al. The young adult hip: extra-articular causes of hip pain and how to pick the winners. J Hip Preserv Surg 2015;2:51-5. 
43 Khan W, Khan M, Alradwan H, et al. Utility of intra-articular hip injections for femoroacetabular impingement: a systematic review. Orthop J Sports Med 2015;3:2325967115601030.

44 Shearer DW, Kramer J, Bozic KJ, et al. Is hip arthroscopy cost-effective for femoroacetabular impingement? Clin Orthop Relat Res 2012;470:1079-89.

45 Martin HD, Palmer IJ. History and physical examination of the hip: the basics. Curr Rev Musculoskelet Med 2013;6:219-25.

46 Martin HD, Kelly BT, Leunig M, et al. The pattern and technique in the clinical evaluation of the adult hip: the common physical examination tests of hip specialists. Arthroscopy 2010;26:161-72.

47 Diamond LE, Dobson FL, Bennell KL, et al. Physical impairments and activity limitations in people with femoroacetabular impingement: a systematic review. Br J Sports Med 2015:49:230-4.

48 Botha N, Warner M, Gimpel M, et al. Movement patterns during a small knee bend test in academy footballers with femoroacetabular impingement (FAI). Health Sci Working Papers 2014;1:1-24.

49 Frank JM, Harris JD, Erickson BJ, et al. Prevalence of femoroacetabular impingement imaging findings in asymptomatic volunteers: a systematic review. Arthroscopy 2015:31:1199-204.

50 Tannast $M$, Fritsch S, Zheng $G$, et al. Which radiographic hip parameters do not have to be corrected for pelvic rotation and tilt? Clin Orthop Relat Res 2015;473:1255-66.

51 Tannast M, Siebenrock KA, Anderson SE. Femoroacetabular impingement: radiographic diagnosis-what the radiologist should know. AJR Am J Roentgenol 2007:188:1540-52

52 Meyer DC, Beck M, Ellis T, et al. Comparison of six radiographic projections to assess femoral head/neck asphericity. Clin Orthop Relat Res 2006;445:181-5.

53 Ross JR, Tannenbaum EP, Nepple JJ, et al. Functional acetabular orientation varies between supine and standing radiographs: implications for treatment of femoroacetabular impingement. Clin Orthop Relat Res 2015;473:1267-73.

54 Kassarjian A, Yoon LS, Belzile E, et al. Triad of MR arthrographic findings in patients with cam-type femoroacetabular impingement. Radiology 2005:236:588-92.

55 Smith TO, Simpson M, Ejindu V, et al. The diagnostic test accuracy of magnetic resonance imaging, magnetic resonance arthrography and computer tomography in the detection of chondral lesions of the hip. Eur J Orthop Surg Traumatol 2013;23:335-44

56 Smith TO, Hilton G, Toms AP, et al. The diagnostic accuracy of acetabular labral tears using magnetic resonance imaging and magnetic resonance arthrography: a meta-analysis. Eur Radiol 2011;21:863-74.

57 Sutter R, Dietrich TJ, Zingg PO, et al. Femoral antetorsion: comparing asymptomatic volunteers and patients with femoroacetabular impingement. Radiology 2012;263:475-83

58 Nötzli H, Wyss T, Stoecklin C, et al. The contour of the femoral head-neck junction as a predictor for the risk of anterior impingement. J Bone Joint Surg Br 2002;84:556-60.

59 Jamali AA, Mladenov K, Meyer DC, et al. Anteroposterior pelvic radiographs to assess acetabular retroversion: high validity of the "cross-over-sign". J Orthop Res 2007;25:758-65

60 Wiberg G. Studies on dysplastic acetabula and congenital subluxation of the hip joint: with special reference to the complication of osteoarthritis. Acta Chir Scand 1939:58:135

61 Alonso-Coello P, Schunemann HJ, Moberg J, et al. GRADE Evidence to Decision (EtD) frameworks: a systematic and transparent approach to making well informed healthcare choices. 1: Introduction. BMJ 2016:353:i2016.

62 Elwyn G, Frosch D, Thomson $R$, et al. Shared decision making: a model for clinical practice. J Gen Intern Med 2012;27:1361-7.

63 Zhang W, Moskowitz RW, Nuki G, et al. OARSI recommendations for the management of hip and knee osteoarthritis, part II: OARSI evidence-based, expert consensus guidelines. Osteoarthr Cartil 2008;16:137-62.
64 Fernandes L, Hagen KB, Bijlsma JW, et al. EULAR recommendations for the non-pharmacological core management of hip and knee osteoarthritis. Ann Rheum Dis 2013;72:1125-35

65 Casartelli NC, Maffiuletti NA, Bizzini M, et al. The management of symptomatic femoroacetabular impingement: what is the rationale for non-surgical treatment? Br J Sports Med 2016:50:511-12.

66 Grzybowski JS, Malloy P, Stegemann C, et al. Rehabilitation following hip arthroscopy-a systematic review. Front Surg 2015:2:21.

67 Cheatham SW, Enseki KR, Kolber MJ. Postoperative rehabilitation after hip arthroscopy: a search for the evidence. J Sport Rehabil 2015;24(4):413-18.

68 Bennell KL, O'Donnell JM, Takla A, et al. Efficacy of a physiotherapy rehabilitation program for individuals undergoing arthroscopic management of femoroacetabular impingement-the FAIR trial: a randomised controlled trial protocol. BMC Musculoskelet Disord 2014;15:1.

69 O'Donnell JM. Femoroacetabular impingement: what happens (in the short term) with no treatment? St Georges Park, UK: Sports Hip, 2016

70 Emara K, Samir W, Motasem el H, et al. Conservative treatment for mild femoroacetabular impingement. J Orthop Surg (Hong Kong) 2011;19:41-5

71 Palmer DH, Ganesh V, Comfort T, et al. Midterm outcomes in patients with cam femoroacetabular impingement treated arthroscopically. Arthroscopy 2012;28:1671-81.

72 Steppacher SD, Anwander H, Zurmuhle CA, et al. Eighty percent of patients with surgical hip dislocation for femoroacetabular impingement have a good clinical result without osteoarthritis progression at 10 years. Clin Orthop Relat Res 2015;473:1333-41.

73 Agricola $\mathrm{R}$, Waarsing JH, Arden NK, et al. Cam impingement of the hip: a risk factor for hip osteoarthritis. Nat Rev Rheumatol 2013;9:630-4.

74 Agricola R, Heijboer MP, Bierma-Zeinstra SM, et al. Cam impingement causes osteoarthritis of the hip: a nationwide prospective cohort study (CHECK). Ann Rheum Dis 2013;72:918-23.

75 Thomas GE, Palmer AJ, Batra RN, et al. Subclinical deformities of the hip are significant predictors of radiographic osteoarthritis and joint replacement in women. A 20 year longitudinal cohort study. Osteoarthritis Cartilage 2014;22:1504-10.

76 Hosnijeh FS, Zuiderwijk M, Versteeg $M$, et al. The shape of the hip joint as a risk factor for osteoarthritis. Osteoarthritis Cartilage 2016;24:S21-2.

77 Lahner M, Walter PA, von Schulze Pellengahr C, et al. Comparative study of the femoroacetabular impingement (FAI) prevalence in male semiprofessional and amateur soccer players. Arch Orthop Trauma Surg 2014;134:1135-41.

78 Haviv B, O'Donnell J. Arthroscopic treatment for symptomatic bilateral cam-type femoroacetabular impingement. Orthopedics 2010;33:874.

79 Griffin DR, Parsons N, Mohtadi NG, et al. A short version of the International Hip Outcome Tool (iHOT-12) for use in routine clinical practice. Arthroscopy 2012:28:611-18

80 Thorborg K, Tijssen M, Habets B, et al. Patient-Reported Outcome (PRO) questionnaires for young to middle-aged adults with hip and groin disability: a systematic review of the clinimetric evidence. Br J Sports Med 2015;49:812.

81 Cella D, Riley W, Stone A, et al. The Patient-Reported Outcomes Measurement Information System (PROMIS) developed and tested its first wave of adult selfreported health outcome item banks: 2005-2008. Journal of clinical epidemiology 2010;63(11):1179-94.

82 Walters SJ, Brazier JE. Comparison of the minimally important difference for two health state utility measures: EQ-5D and SF-6D. Qual Life Res 2005;14:1523-32.

83 Jenkinson C, Layte R. Development and testing of the UK SF-12. J Health Serv Res 1997:2:14-18.

84 Griffin DR, Dickenson EJ, O'Donnell JM, et al. Infographic. The Warwick Agreement on femoroacetabular impingement syndrome (FAI syndrome): an international consensus statement. Br J Sports Med 2016;50:1169-76. 